\title{
Nonlinear Mixed Effects Model Analysis of the Pharmacokinetics of Metoprolol in Routinely Treated Japanese Patients
}

\author{
Masato Taguchi, ${ }^{a}$ Takashi Nozawa, ${ }^{b}$ Kouichi Mizumaki, ${ }^{b}$ Hiroshi Inoue, ${ }^{b}$ Katsutoshi Tahara, ${ }^{a}$ \\ Chihiro TAKesono, ${ }^{a}$ and Yukiya Hashimoto*,a \\ ${ }^{a}$ Graduate School of Pharmaceutical Sciences, Toyama Medical and Pharmaceutical University; and ${ }^{b}$ Second Department \\ of Internal Medicine, Faculty of Medicine, Toyama Medical and Pharmaceutical University; 2630 Sugitani, Toyama \\ 930-0194, Japan. Received April 5, 2004; accepted July 23, 2004
}

This study was performed to estimate the mean pharmacokinetic parameters of routinely administered metoprolol in middle-aged and elderly Japanese patients. Whole blood concentration data (65 samples) at steady-state following repetitive administration to 34 patients were analyzed using a nonlinear mixed effects model. A one-compartment model was parameterized in terms of oral clearance $(C L / F)$ and apparent volume of distribution $(V / F)$. We evaluated the effect of polymorphic alleles $(C Y P 2 D 6 * 2, C Y P 2 D 6 * 10, C Y P 2 C 19 * 2$ and $C Y P 2 C 19 * 3)$, age, gender, and heart failure on the pharmacokinetic parameters of metoprolol. The $C L / F$ value in patients homozygous for the $C Y P 2 D 6 * 10$ allele was $64 \%$ lower than that in patients with a $C Y P 2 D 6 * 1 / * 1$ or $* 1 / * 2$ genotype. The $C L / F$ value in older $(>70$ years old $)$ patients was $26 \%$ lower than that in younger $(\leq 70$ years old) patients. In addition, the $V / F$ value in patients homozygous for the $C Y P 2 D 6 * 10$ allele was $25 \%$ lower than that in patients with the $C Y P 2 D 6 * 1 / * 1$ or $* 1 / * 2$ genotype. On the other hand, the CYP2C19 genotype, gender, and heart failure showed no significant effects on the pharmacokinetics of metoprolol. The results suggest that the pharmacokinetic variability of metoprolol in Japanese extensive metabolizers of CYP2D6 is very large, probably because $C Y P 2 D 6 * 10$ is responsible not only for the decreased systemic clearance (CL) but also for the increased bioavailability (F) of the drug.

Key words aging; Japanese patient; metoprolol; nonlinear mixed effects model (NONMEM); pharmacokinetics; whole blood concentration

CYP2D6 genetic polymorphisms have been extensively studied, and more than 40 variants have been documented. ${ }^{1)}$ In addition, a pronounced interethnic difference is present in the allele frequencies of individual variants of CYP2D6. Poor metabolism due to CYP2D6 occurs in 7\% of Caucasians but less than $1 \%$ of Asians. ${ }^{2,3)}$ Among Asian extensive metabolizers, the three most common alleles of the CYP2D6 gene are $C Y P 2 D 6^{*} 1, C Y P 2 D 6^{*} 2$, and $C Y P 2 D 6^{*} 10 .^{4)} C Y P 2 D 6^{*} 1$ produces a wild-type protein with $\mathrm{Pro}^{34}, \mathrm{Arg}^{296}$, and $\mathrm{Ser}^{486}$. $C Y P 2 D 6 * 2$ produces a mutant enzyme with $\mathrm{Arg}^{296} \mathrm{Cys}$ and Ser ${ }^{486} \mathrm{Thr}$ amino acid substitutions, ${ }^{5}$ and $C Y P 2 D 6 * 10$ produces an enzyme with $\mathrm{Pro}^{34} \mathrm{Ser}$ and $\mathrm{Ser}^{486} \mathrm{Thr}$ amino acid substitutions. ${ }^{6,7)}$ The allele frequencies of $C Y P 2 D 6^{*} 1, * 2$, and $* 10$ in Asian subjects are $23-45 \%, 9-20 \%$, and 38 $54 \%$, respectively, whereas the allele frequencies of CYP $2 D 6 * 1, * 2$, and $* 10$ in Caucasian subjects are $33-40 \%$, $22-34 \%$, and $1-8 \%$, respectively. ${ }^{1,8-10)}$ Recently, we have examined the effect of $C Y P 2 D 6^{*} 2$ and $C Y P 2 D 6^{*} 10$ on the steady-state plasma concentration of routinely administered metoprolol in middle-aged and elderly Japanese patients, and found that $C Y P 2 D 6^{*} 10$ but not $C Y P 2 D 6^{*} 2$ is largely responsible for the pharmacokinetic variability of metoprolol. ${ }^{11)}$

Metoprolol is extensively metabolized in the liver. Therefore, the orally administered metoprolol is subjected to avid hepatic first-pass extraction. ${ }^{12,13)}$ Wilkinson and Shand have stated as follows: "since drug distributed in the erythrocyte usually equilibrates rapidly with that in the plasma, and any drug in the red blood cells is generally available for hepatic extraction, and blood rather than plasma concentrations must be used when any physiological interpretation is placed on the clearance process." ${ }^{, 14)}$ Previously, we have reported that the $V / F$ value of metoprolol in Japanese patients with CYP2D6*10 is lower than that in patients without
$C Y P 2 D 6^{*} 10$, and suggested that hepatic first-pass extraction may be decreased in patients with $C Y P 2 D 6^{*} 10 .{ }^{11)}$ Therefore, in this study, we analyzed newly measured blood concentrations of metoprolol to evaluate hepatic first-pass extraction and bioavailability $(F)$ of the drug.

The protein binding of metoprolol in human plasma is only about $12 \%{ }^{13)}$ Therefore, it is unlikely that the alteration of plasma unbound fraction of the drug is responsible for the pharmacokinetic variability in patients. On the other hand, several studies reported on the effect of age on the pharmacokinetics of metoprolol. Regårdh et al. found that there is no effect of age on the pharmacokinetics of metoprolol. ${ }^{15)}$ In contrast, Kendall et al. reported that the mean plasma levels of metoprolol tend to be higher in elderly normotensive subjects (62-77 years old) than in middle-aged hypertensive patients (50-61 years old) and young healthy volunteers $\left(20-26\right.$ years old). ${ }^{16}$ ) Rendic suggested that not only CYP2D6 but also CYP2C19 contributes to the metabolism of metoprolol as well as propranolol. ${ }^{17)}$ In addition, Luzier et $a l$. reported that the oral clearance of metoprolol in young white women is significantly lower than that in young white men. ${ }^{18)}$ However, the effects of aging and gender on the pharmacokinetics or the contribution of CYP2C19 to the metabolism of metoprolol is unclear for the Japanese population. Accordingly, this study was designed to investigate the effect of these factors on the oral clearance $(C L / F)$ and apparent volume of distribution $(V / F)$ of metoprolol, where a pharmacokinetic analysis was performed using a nonlinear mixed effects model (NONMEM) program.

\section{MATERIALS AND METHODS}

Subjects and Study Design Thirty-four subjects in this 
study were the same one who participated in a previous study on plasma metoprolol concentration, and their characteristics have been previously described. ${ }^{11)}$ In brief, the subjects were Japanese patients consisting of 21 males and 13 females between 56 and 83 (mean \pm S.D.: 69.6 \pm 7.6 ) years old, and their mean body weight $( \pm$ S.D.) was $60.0 \pm 11.0 \mathrm{~kg}$. No patients had null alleles of CYP2D6 $(* 4, * 5, * 14)$, and they could be divided into five groups on the basis of CYP2D6 genotypes. ${ }^{11)}$ Nine patients were homozygous for the CYP $2 D 6^{*} 1$ allele (Group 1a), and five were heterozygous for the CYP2D6*1/*2 alleles (Group 1b). Finally, seven patients were heterozygous for the CYP $2 D 6^{*} 1 / * 10$ alleles (Group 2a), and six patients were heterozygous for the CYP $2 D 6 * 2 / * 10$ alleles (Group 2b). Seven patients were homozygous for the CYP $2 D 6^{*} 10$ allele (Group 3 ). In this study, five patients had symptomatic congestive heart failure (CHF): four patients were characterized as New York Heart Association (NYHA) class II, and one patient was NYHA class III. However, no patients had severe hepatic or renal failure, and none had received any potent inhibitor of CYP2D6 (e.g. amiodarone or quinidine). These patients had been routinely treated with oral administration of a rapid-release preparation of metoprolol tartrate $\left(\right.$ Seloken ${ }^{\circledR}$ Tablets, AstraZeneca, Tokyo, Japan) at doses between 40 and $120 \mathrm{mg} / \mathrm{d}$, and the drug was administered twice a day in 8 patients and three times a day in 26 patients. The peak blood concentration occurs within $2 \mathrm{~h}$ after dosing of a rapid-release preparation of metoprolol tartrate. ${ }^{19)}$ Therefore, blood samples at steady-state following repetitive administration were obtained between 2 and $4.5 \mathrm{~h}$ after dosing for all $34 \mathrm{pa}-$ tients. Additional blood samples just before dosing were obtained from 31 patients. All patients gave written consent to participate in this study, which was approved by the ethics committee of Toyama Medical and Pharmaceutical University.

Genotyping of CYP2C19 Genomic DNA in 34 patients was isolated from peripheral blood, and was stored at $-80^{\circ} \mathrm{C} .{ }^{11)}$ The $C Y P 2 C 19^{*} 1$ (wild-type) allele and two defective allelic variants, $C Y P 2 C 19 * 2$ and $C Y P 2 C 19 * 3$, were determined using the polymerase chain reaction-restriction fragment length polymorphism method as described by Lamba et al. ${ }^{20)}$ The homozygotes of CYP $2 C 19 * 1$ and the heterozygotes of mutant alleles $(C Y P 2 C 19 * 1 / * 2$ and $* 1 / * 3)$ were defined as extensive metabolizers of CYP2C19. The homozygotes for mutant alleles $(C Y P 2 C 19 * 2 / * 2, * 2 / * 3$, and $* 3 / * 3)$ were defined as poor metabolizers of CYP2C19.

Assay of Metoprolol in Whole Blood The blood metoprolol concentration was measured using HPLC as described by Hamelin et al. with minor modifications. ${ }^{21)}$ Briefly, whole blood samples $(0.5 \mathrm{ml})$ were mixed with an identical volume of distilled water to hemolyze the blood cells. After alkalinization with $3 \mathrm{ml}$ of glycine buffer $(0.1 \mathrm{M}$, saturated with $\mathrm{NaCl}, \mathrm{pH}$ 10.6), the samples were mildly extracted with $5 \mathrm{ml}$ of diethylether for $20 \mathrm{~min}$. Metoprolol was back-extracted from the organic phase with $0.2 \mathrm{ml}$ of $0.05 \mathrm{~N} \mathrm{HCl}$. A $50 \mu \mathrm{l}$ aliquot of $\mathrm{HCl}$ solution was injected onto the HPLC system. The column was a COSMOSIL 5C18-AR-II $(15 \mathrm{~cm} \times$ $4.6 \mathrm{~mm}$; i.d. $4.5 \mu \mathrm{m}$ particle size; Nacalai tesque). The mobile phase consisted of $10 \mathrm{~mm} \mathrm{KH} \mathrm{KO}_{4}$ /acetonitrile (90.5/9.5) that contained $0.6 \%(\mathrm{wt} / \mathrm{vol})$ triethylamine adjusted to $\mathrm{pH} 3.3$ with phosphoric acid. The peaks were monitored at an exci- tation wavelength of $272 \mathrm{~nm}$ and an emission wavelength of $303 \mathrm{~nm}$. The coefficient of variation for this assay was $2.1 \%$ and $1.3 \%$ at whole blood concentrations of $5 \mathrm{ng} / \mathrm{ml}$ and $50 \mathrm{ng} / \mathrm{ml}$, respectively. The detection limit for metoprolol was $2 \mathrm{ng} / \mathrm{ml}$ for its whole blood concentration.

Nonlinear Mixed Effects Model of the Pharmacokinetics of Metoprolol The time required to reach the peak concentration after oral administration of a rapid-release preparation of metoprolol (e.g. Seloken ${ }^{\circledR}$ Tablets) is known to be short. ${ }^{19)}$ Therefore, the one-compartment model with repetitive bolus dosing was parameterized in terms of $C L / F$ and $V / F^{22}{ }^{2}$ For the simplest basic model (Model 1), the oral clearance in the $i$ th individual $\left(C L / F_{i}\right)$ was modeled using the following equation:

$$
C L / F_{i}=\theta_{1} \cdot W T_{i} \cdot\left(1+\eta_{C L / F}\right)
$$

where $\theta_{1}$ is the predicted population mean of the oral clearance, $W T_{i}$ is the individual body weight, and $\eta_{C L / F_{i}}$ is a random variable distributed with a mean of zero and variance of $\omega_{C L / F}^{2}$. The apparent volume of distribution in the $i$ th individual $\left(V / F_{i}\right)$ was modeled using the following equation:

$$
V / F_{i}=\theta_{2} \cdot W T \cdot\left(1+\eta_{V / F_{i}}\right)
$$

where $\theta_{2}$ is the predicted population mean of the apparent distribution volume, and $\eta_{V / F}$ is a random variable with a mean of zero and variance of $\omega_{V / F}^{2}$. Finally, the $j$ th observed blood concentration in the $i$ th patient $\left(C b_{i j}\right)$ was assumed to be randomly and normally distributed from the $j$ th predicted blood concentration in the $i$ th patient $\left(C b_{i j}^{*}\right)$ :

$$
C b_{i j}=C b_{i j}^{*}+\varepsilon_{i j}
$$

where $\varepsilon_{i j}$ is a random variable that describes intraindividual variability with a mean of zero and variance of $\sigma^{2}$.

Table 1 summarizes the 16 analysis models used in this study. The effects of body weight $(W T)$ on $C L / F$ and $V / F$ were evaluated by Model 2 and Model 3, respectively. The effects of the $C Y P 2 D 6^{*} 10$ genotype on $C L / F$ and $V / F$ were evaluated by Models 4, 5, 6, and 7; where $G 1=1$ and $G 3=0$ for the Group 1 patients with $C Y P 2 D 6^{*} 1 / * 1$ and $* 1 / * 2$, $G 1=0$ and $G 3=0$ for the Group 2 patients with $C Y P 2 D 6^{*} 1 / * 10$ and $* 2 / * 10$, and $G 1=0$ and $G 3=1$ for the Group 3 patients with $C Y P 2 D 6^{*} 10 / * 10$. The effects of age $(A G E)$ on $C L / F$ and $V / F$ were evaluated by Models 8,9 , and 10 ; where $A G E>70$ is one for the older ( $71-83$ years old) patients, and zero for the younger (56-70 years old) patients. The effects of gender on $C L / F$ and $V / F$ were evaluated by Models 11 and 12, respectively; where $S E X$ is one for females and zero for males. The effects of heart failure on $C L / F$ and $V / F$ were evaluated by Models 13 and 14, respectively; where $C H F$ is one for patients with NYHA II-III and zero for patients without heart failure. In addition, the effect of the $C Y P 2 D 6^{*} 2$ genotype on $C L / F$ was evaluated by Model 15 ; where $2 D 6^{*} 2$ is one for patients with $C Y P 2 D 6^{*} 2$ and zero for patients without $C Y P 2 D 6^{*} 2$. The effect of poor metabolizer genotypes of CYP2C19 on $C L / F$ was evaluated by Model 16; where $2 C 19 P M$ is one for poor metabolizers of CYP2C19 and zero for extensive metabolizers of CYP2C19.

Data Analysis Data analysis was performed with NONMEM software (double precision NONMEM Version $\mathrm{V}$ Level 1.1, PREDPP Version IV Level 1.1, and NM-TRAN Version III Level 1.1) ${ }^{23)}$ running on a mainframe UNIX com- 
puter at the Kyoto University Data Processing Center. In the present study, we used a first-order estimation method and the NONMEM-PREDPP library subroutines ADVAN1 and TRANS2 for the one-compartment model with bolus dosing. ${ }^{23)}$ Statistical significance of the parameters was evaluated by the likelihood ratio test using the minimum value of the objective function ( $-2 \log$ likelihood) produced by NONMEM. ${ }^{23)}$ That is, when the difference of $-2 \log$ likelihood (LLD) between two models allowing a parameter of interest freely estimated versus a fixed hypothetical value was greater than 3.84, the parameter value was considered to be statistically significant $(p<0.05)$. In addition, NONMEM provides estimates of the standard error (S.E.) for all the parameters, and S.E. can be used to define $95 \%$ confidence intervals $(\mathrm{CI})$ for true parameter values: $95 \% \mathrm{CI}=($ the estimated parameter value) $\pm 1.96 \cdot$ S.E. $^{23)}$

\section{RESULTS}

Figure 1 shows the relationship between the measured blood concentration and plasma concentration of metoprolol in 34 Japanese patients. The large interindividual variability was observed in the blood/plasma concentration $(\mathrm{B} / \mathrm{P})$ ratio. Figure 2 shows the observed blood concentrations of metoprolol in the 34 patients. The blood metoprolol concentrations of Group 1a (patients with $C Y P 2 D 6^{*} 1 / * 1$ ) were similar to those of Group $1 \mathrm{~b}$ (patients with $C Y P 2 D 6^{*} 1 / * 2$ ). There was little difference between the blood concentrations of Group 2a (patients with $C Y P 2 D 6^{*} 1 / * 10$ ) and those of Group $2 \mathrm{~b}$ (patients with $C Y P 2 D 6^{*} 2 / * 10$ ), and higher levels of metoprolol were observed in Group 2 (Group 2a plus 2b) compared with Group 1 (Group 1a plus 1b). The blood levels of Group 3 (patients with $C Y P 2 D 6 * 10 / * 10$ ) were considerably higher than those of Groups 1 and 2.

Sixty-five blood metoprolol concentration data points from 34 patients were analyzed using 16 pharmacokinetic models, and the LLD values are summarized in Table 1 . The population mean pharmacokinetic parameters, $\theta_{1}$ and $\theta_{2}$, for Model 1 were estimated to be $0.811 \mathrm{l} / \mathrm{h} / \mathrm{kg}$ and $5.171 / \mathrm{kg}$, respectively. The $\omega_{C L / F}$ and $\omega_{V / F}$ values for Model 1 were estimated to be $69.7 \%$ and $38.6 \%$, respectively. The $\theta_{3}$ value for Model 2 and the $\theta_{4}$ value for Model 3 were estimated to be 0.722 and 1.15, respectively. However, the LLD values for Models 2 and 3 did not reach a statistically significant level (Table 1).

The $\theta_{5}$ and $\omega_{C L / F}$ values for Model 4 were estimated to be $0.377 \mathrm{l} / \mathrm{h} / \mathrm{kg}$ and $36.3 \%$, respectively, and the LLD value was $54.35(p<0.001)$ (Table 1), indicating a significant effect of the $C Y P 2 D^{*} 10$ allele on the pharmacokinetic variability of metoprolol. However, no further significant improvement by the introduction of $\theta_{6}$ was observed in the LLD value for Model 5 (Table 1). The $\theta_{7}$ and $\omega_{V / F}$ values for Model 6 were estimated to be $0.7381 / \mathrm{kg}$ and $13.2 \%$, respectively, and the LLD value was $6.36(p<0.025)$. No further improvement by the introduction of $\theta_{8}$ was observed in the LLD value for Model 7 (Table 1).

The $\theta_{9}$ value was estimated to be 0.0133 for Model 8; however, the LLD value did not reach a statistically significant level (Table 1). In contrast, the $\theta_{10}$ value for Model 9 was estimated to be 0.739 , and the LLD value was 6.76 $(p<0.01)$, which indicated that the $C L / F$ value in the older $(>70$ years old) patients was significantly lower than that in

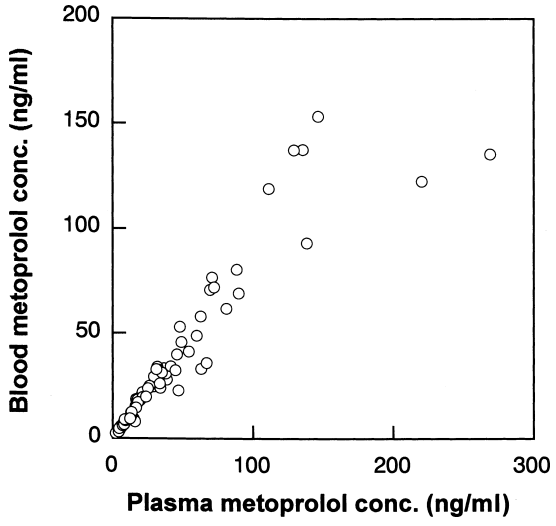

Fig. 1. Relationship between the Measured Blood Concentration and the Plasma Concentration of Metoprolol in 34 Japanese Patients

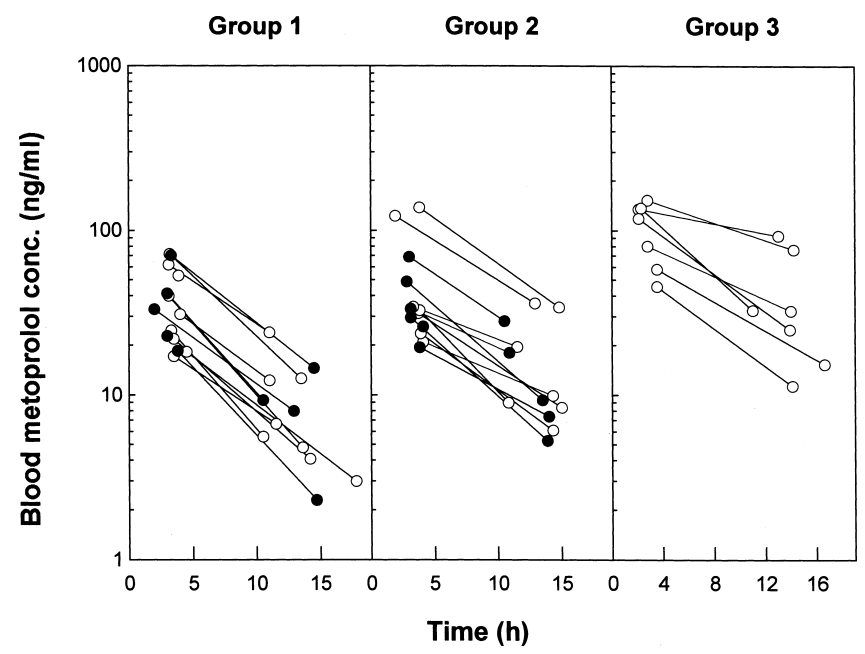

Fig. 2. Whole Blood Concentrations of Metoprolol at the Steady-State in Groups 1, 2, and 3

Open circles: $C Y P 2 D 6^{*} 1 / * 1$ (Group 1a), CYP $2 D 6 * 1 / * 10$ (Group 2a), or $C Y P 2 D 6 * 10 / * 10$ (Group 3); solid circles: CYP2D6*1/*2 (Group 1b) or CYP2D6*2/*10 (Group 2b)

the younger ( $\leq 70$ years old) patients. The $\theta_{11}$ value for Model 10 was estimated to be 0.888 , and the LLD value in Model 10 was 1.13 . Thus no significant effect of aging on $V / F$ was detected for Model 10 (Table 1).

The $\theta_{12}$ value for Model 11 and the $\theta_{13}$ value for Model 12 were estimated to be 0.848 and 0.951 , respectively. The $\theta_{14}$ value for Model 13 and the $\theta_{15}$ value for Model 14 were estimated to be 0.863 and 1.04 , respectively. The $\theta_{16}$ value for Model 15 and the $\theta_{17}$ value for Model 16 were estimated to be 1.19 and 0.974 , respectively. However, the LLD values in Models 11-16 did not reach a statistically significant level (Table 1). Accordingly, Model 9 was selected as the final model to describe the pharmacokinetics of routinely administered metoprolol in middle-aged and elderly Japanese patients.

Table 2 shows the final estimates of population pharmacokinetic parameters of metoprolol and their 95\% CI for Model 9. The final $C L / F\left(\theta_{1}\right)$ and $V / F\left(\theta_{2}\right)$ values in Group 2 were estimated to be $0.9381 / \mathrm{h} / \mathrm{kg}$ and $4.521 / \mathrm{kg}$, respectively. On the other hand, the $C L / F$ value in Group $1\left(\theta_{1}+\theta_{5}\right)$ was 2.76 times as large as that in Group $3\left(\theta_{1}-\theta_{5}\right)$. In addition, the mean $C L / F$ value in the older ( $>70$ years old) patients was 
Table 1. Analysis Models for the Pharmacokinetic Parameters of Metoprolol

\begin{tabular}{|c|c|c|c|}
\hline Model & Formula & No. of $\theta \mathrm{s}$ & LLD \\
\hline 1 & $\begin{array}{l}C L / F_{i}=\theta_{1} \cdot W T_{i} \cdot\left(1+\eta_{C L / F}\right) \\
V / F_{i}=\theta_{2} \cdot W T_{i} \cdot\left(1+\eta_{V / F}\right)\end{array}$ & 2 & - \\
\hline 2 & $\begin{array}{l}C L / F_{i}=\theta_{1} \cdot W T_{i}^{\theta_{3}} \cdot\left(1+\eta_{C L / F}\right) \\
V / F_{i}=\theta_{2} \cdot W T_{i} \cdot\left(1+\eta_{V / F_{i}}\right)\end{array}$ & 3 & 1.25 vs. Model 1 \\
\hline 3 & $\begin{array}{l}C L / F_{i}=\theta_{1} \cdot W T_{i} \cdot\left(1+\eta_{C L / F}\right) \\
V / F_{i}=\theta_{2} \cdot W T_{i}^{\theta_{4}}\left(1+\eta_{V / F}\right)\end{array}$ & 3 & 0.33 vs. Model 1 \\
\hline 4 & $\begin{array}{l}C L / F_{i}=\left(\theta_{1}+\theta_{5} \cdot G 1-\theta_{5} \cdot G 3\right) \cdot W T_{i} \cdot\left(1+\eta_{C L / F}\right) \\
V / F_{j}=\theta_{2} \cdot W T_{j} \cdot\left(1+\eta_{U / F}\right)\end{array}$ & 3 & 54.35 vs. Model 1 \\
\hline 5 & $\begin{array}{l}C L / F_{i}=\left(\theta_{1}+\theta_{5} \cdot G 1-\theta_{6} \cdot G 3\right) \cdot W T_{i} \cdot\left(1+\eta_{C L / F}\right) \\
V / F_{i}=\theta_{2} \cdot W T_{i} \cdot\left(1+\eta_{V / F}\right)\end{array}$ & 4 & 2.65 vs. Model 4 \\
\hline 6 & $\begin{array}{l}C L / F_{i}=\left(\theta_{1}+\theta_{5} \cdot G 1-\theta_{5} \cdot G 3\right) \cdot W T_{i} \cdot\left(1+\eta_{C L / F}\right) \\
V / F_{i}=\left(\theta_{2}+\theta_{7} G 1-\theta_{7} \cdot G 3\right) \cdot W T_{i} \cdot\left(1+\eta_{U / F}\right)\end{array}$ & 4 & 6.36 vs. Model 4 \\
\hline 7 & $\begin{array}{l}C L / F_{i}=\left(\theta_{1}+\theta_{5} \cdot G 1-\theta_{5} \cdot G 3\right) \cdot W T_{i} \cdot\left(1+\eta_{C L / F}\right) \\
V / F_{i}=\left(\theta_{2}+\theta_{7} \cdot G 1-\theta_{8} \cdot G 3\right) \cdot W T_{i} \cdot\left(1+\eta_{V / F}\right)\end{array}$ & 5 & 1.27 vs. Model 6 \\
\hline 8 & $\begin{array}{l}C L / F_{i}=\left(\theta_{1}+\theta_{5} \cdot G 1-\theta_{5} \cdot G 3\right) \cdot\left(1-\theta_{9} \cdot(A G E-70)\right) \cdot W T_{i} \cdot\left(1+\eta_{C L / F_{i}}\right) \\
V / F_{i}=\left(\theta_{2}+\theta_{7} \cdot G 1-\theta_{7} \cdot G 3\right) \cdot W T_{i} \cdot\left(1+\eta_{V / F}\right)\end{array}$ & 5 & 3.50 vs. Model 6 \\
\hline 9 & $\begin{array}{l}C L / F_{i}=\left(\theta_{1}+\theta_{5} \cdot G 1-\theta_{5} \cdot G 3\right) \cdot \theta_{10}^{A G E>70} \cdot W T_{i} \cdot\left(1+\eta_{C L / F_{i}}\right) \\
V / F_{i}=\left(\theta_{2}+\theta_{7} \cdot G 1-\theta_{7} \cdot G 3 \cdot W T_{i} \cdot\left(1+\eta_{V / F}\right)\right.\end{array}$ & 5 & 6.76 vs. Model 6 \\
\hline 10 & $\begin{array}{l}C L / F_{i}=\left(\theta_{1}+\theta_{5} \cdot G 1-\theta_{5} \cdot G 3\right) \cdot \theta_{10}^{A G E>70} \cdot W T_{i} \cdot\left(1+\eta_{C L / F}\right) \\
V / F_{i}=\left(\theta_{2}+\theta_{7} \cdot G 1-\theta_{7} \cdot G 3\right) \cdot \theta_{11}^{A G E>70} \cdot W T_{i} \cdot\left(1+\eta_{C L / F}\right)\end{array}$ & 6 & 1.13 vs. Model 9 \\
\hline 11 & $\begin{array}{l}C L / F_{i}=\left(\theta_{1}+\theta_{5} \cdot G 1-\theta_{5} \cdot G 3\right) \cdot \theta_{10}^{A G E>70} \cdot \theta_{12}^{S E X} \cdot W T_{i} \cdot\left(1+\eta_{V / F}\right) \\
V / F_{i}=\left(\theta_{2}+\theta_{7} \cdot G 1-\theta_{7} \cdot G 3\right) \cdot W T_{i} \cdot\left(1+\eta_{V / F}\right)\end{array}$ & 6 & 2.75 vs. Model 9 \\
\hline 12 & $\begin{array}{l}C L / F_{i}=\left(\theta_{1}+\theta_{5} \cdot G 1-\theta_{5} \cdot G 3\right) \cdot \theta_{10}^{A G E>70} \cdot W T_{i} \cdot\left(1+\eta_{C L / F}\right) \\
V / F_{i}=\left(\theta_{2}+\theta_{7} \cdot G 1-\theta_{7} \cdot G 3\right) \cdot \theta_{13}^{S E X} \cdot W T_{i} \cdot\left(1+\eta_{V / F}\right)\end{array}$ & 6 & 0.21 vs. Model 9 \\
\hline 13 & $\begin{array}{l}C L / F_{i}=\left(\theta_{1}+\theta_{5} \cdot G 1-\theta_{5} \cdot G 3\right) \cdot \theta_{10}^{A G E>70} \cdot \theta_{14}^{C H F} \cdot W T_{i} \cdot\left(1+\eta_{C L / F}\right) \\
V / F_{i}=\left(\theta_{2}+\theta_{7} \cdot G 1-\theta_{7} \cdot G 3\right) \cdot W T_{i} \cdot\left(1+\eta_{V / F}\right)\end{array}$ & 6 & 1.19 vs. Model 9 \\
\hline 14 & $\begin{array}{l}C L / F_{i}=\left(\theta_{1}+\theta_{5} \cdot G 1-\theta_{5} \cdot G 3\right) \cdot \theta_{10}^{A G E>70} \cdot W T_{i} \cdot\left(1+\eta_{C L / F}\right) \\
V / F_{i}=\left(\theta_{2}+\theta_{7} \cdot G 1-\theta_{7} \cdot G 3\right) \cdot \theta_{15}^{C H F} \cdot W T_{i} \cdot\left(1+\eta_{V / F}\right)\end{array}$ & 6 & 0.05 vs. Model 9 \\
\hline 15 & $\begin{array}{l}C L / F_{i}=\left(\theta_{1}+\theta_{5} \cdot G 1-\theta_{5} \cdot G 3\right) \cdot \theta_{10}^{A G E>70} \cdot \theta_{16}^{2 D 6^{* 2}} \cdot W T_{i} \cdot\left(1+\eta_{C L / F}\right) \\
V / F_{i}=\left(\theta_{2}+\theta_{7} \cdot G 1-\theta_{7} \cdot G 3\right) \cdot W T_{i} \cdot\left(1+\eta_{U / F}\right)\end{array}$ & 6 & 2.17 vs. Model 9 \\
\hline 16 & $\begin{array}{l}C L / F_{i}=\left(\theta_{1}+\theta_{5} \cdot G 1-\theta_{5} \cdot G 3\right) \cdot \theta_{10}^{A G E}>70 \cdot \theta_{17}^{2 C 19 P M} \cdot W T_{i} \cdot\left(1+\eta_{C L / F}\right) \\
V / F_{i}=\left(\theta_{2}+\theta_{7} \cdot G 1-\theta_{7} \cdot G 3\right) \cdot W T_{i} \cdot\left(1+\eta_{V / F}\right)\end{array}$ & 6 & 0.05 vs. Molde 9 \\
\hline
\end{tabular}

Table 2. Population Pharmacokinetic Parameters of Metoprolol Estimated by Model 9

\begin{tabular}{llcc}
\hline \hline \multicolumn{2}{c}{ Parameters } & Estimates & $95 \% \mathrm{CI}$ \\
\hline$\theta_{1}$ & $(1 / \mathrm{h} / \mathrm{kg})$ & 0.938 & $(0.835-1.04)$ \\
$\theta_{2}$ & $(1 / \mathrm{kg})$ & 4.52 & $(3.86-5.18)$ \\
$\theta_{5}$ & $(1 / \mathrm{h} / \mathrm{kg})$ & 0.439 & $(0.328-0.550)$ \\
$\theta_{7}$ & $(1 / \mathrm{kg})$ & 0.637 & $(0.153-1.12)$ \\
$\theta_{10}$ & & 0.739 & $(0.600-0.878)$ \\
$\omega_{C L / F}$ & $(\%)$ & 29.7 & $(21.7-36.1)$ \\
$\omega_{V / F}$ & $(\%)$ & 17.1 & $(0.00-25.7)$ \\
$\sigma$ & $(\mathrm{ng} / \mathrm{ml})$ & 4.54 & $(1.79-6.16)$ \\
\hline
\end{tabular}

estimated to be $73.9 \%\left(\theta_{10}\right)$ of that in the younger $(\leq 70$ years old) patients. The $V / F$ value in Group $1\left(\theta_{2}+\theta_{7}\right)$ was 1.33 times as large as that in Group $3\left(\theta_{2}-\theta_{7}\right)$. The final $\omega_{C L / F}$ and $\omega_{V / F}$ values were $29.7 \%$ and $17.1 \%$, respectively, which were much smaller than those for Model 1.

Figure 3 shows the effect of $C Y P 2 D 6^{*} 10$, age, gender, and cardiac function on the individual $C L / F$ values of metoprolol for the 34 patients, where the pharmacokinetic parameters in individual patients were obtained from population estimates for Model 9 according to Bayes' theorem using the NONMEM posthoc option. Significant effects of the CYP $2 D 6^{*} 10$ genotype and aging were observed in the individual $C L / F$ values, whereas no significant effect of gender and cardiac function was observed (Fig. 3). Figure 4 shows the effect of $C Y P 2 D 6^{*} 10$, age, gender, and cardiac function on the individual $V / F$ values of metoprolol in 34 patients. A significant

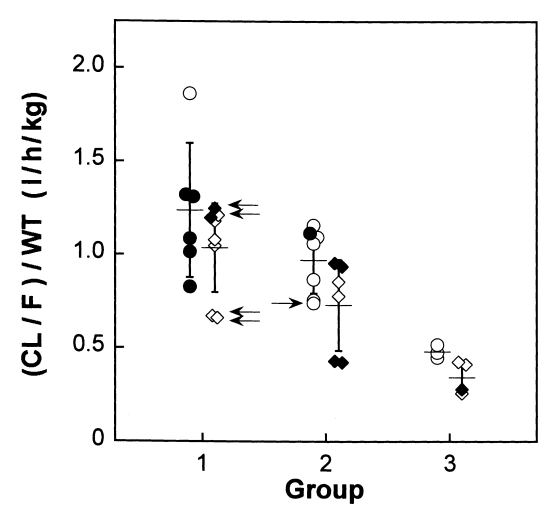

Fig. 3. Effect of $C Y P 2 D 6^{*} 10$, Age, Gender, and Heart Failure on the Oral Clearance of Metoprolol

Circles indicate the younger ( $56-70$ years old) patients, and diamonds indicate the older ( $71-83$ years old) patients in each Group. Open symbols: male patients; solid symbols: female patients. The arrows indicate the patients with NYHA class II or III. Bars indicate the mean \pm S.D. for each group.

effect of the $C Y P 2 D 6^{*} 10$ genotype was observed on the individual $V / F$ values, whereas no significant effect of gender, age, and cardiac function was observed (Fig. 4). Figure 5 shows the effect of $C Y P 2 D 6^{*} 2$ and the CYP2C19 genotype on the individual $C L / F$ values of metoprolol in 34 patients. The $C L / F$ values in patients with $C Y P 2 D 6^{*} 2$ were similar to those in patients without $C Y P 2 D 6^{*} 2$. In addition, the $C L / F$ values for poor metabolizers of CYP2C19 were similar to those for extensive metabolizers of CYP2C19. 


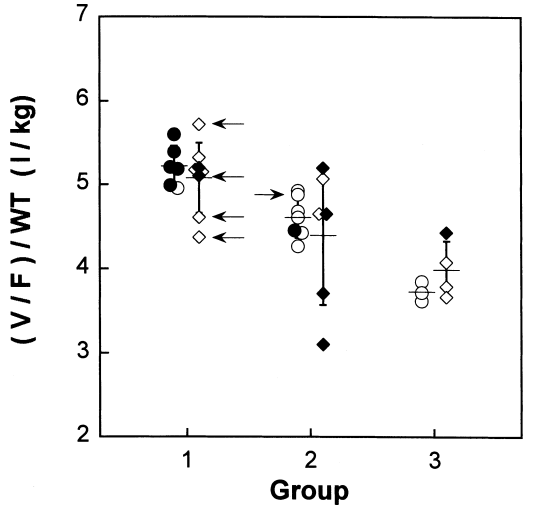

Fig. 4. Effect of $C Y P 2 D 6 * 10$, Age, Gender, and Heart Failure on the Apparent Distribution Volume of Metoprolol

Circles indicate the younger ( $56-70$ years old) patients, and diamonds indicates the older ( $71-83$ years old) patients in each Group. Open symbols: male patients; solid symbols: female patients. The arrows indicate patients with NYHA class II or III. Bars indicate the mean \pm S.D. for each group

\section{DISCUSSION}

In this study, we measured the concentrations of metoprolol in whole blood obtained from 34 middle-aged and elderly Japanese patients, and estimated the $C L / F$ and $V / F$ of the drug using the NONMEM program. The present study confirmed the previous findings ${ }^{11)}$ that the $C L / F$ and $V / F$ values in patients with the CYP $2 D 6^{*} 10$ allele were significantly lower than those in patients without it (Table 1, Figs. 2, 3). In addition, the $C L / F$ value in the older ( $>70$ years old) patients was lower than in the younger $(\leq 70$ years old) patients (Table 1, Fig. 2). On the other hand, the CYP2D $6 * 2$ allele, CYP2C19 genotype, gender, and heart failure showed no significant effects on the pharmacokinetics of metoprolol (Table 1, Figs. 2-4). The mean pharmacokinetic parameters of metoprolol estimated in the present study were comparable with those in the previous report, ${ }^{11)}$ although the considerable interindividual variability was observed in the $\mathrm{B} / \mathrm{P}$ ratio of the drug (Table 2, Fig. 1).

Fractional systemic bioavailability $(F)$ is determined by the fraction of drugs absorbed from the gastrointestinal tract $\left(F_{\text {abs }}\right)$ and the fraction that escapes hepatic first-pass extraction $\left(F_{\mathrm{h}}\right)$ as follows:

$$
F=F_{\text {abs }} \cdot F_{\mathrm{h}}
$$

Metoprolol is virtually completely absorbed from the gastrointestinal tract after oral administration, and is metabolized almost exclusively in the liver. ${ }^{12,13)}$ Therefore, assuming that the gastrointestinal absorption is complete $\left(F_{\text {abs }}=1\right), F$ can be described by the following equation according to the well-stirred model ${ }^{24)}$ :

$$
F=F_{\mathrm{h}}=\frac{Q_{\mathrm{h}}}{Q_{\mathrm{h}}+f_{\mathrm{u}} \cdot C L_{\text {int }}}
$$

where $Q_{\mathrm{h}}$ is hepatic blood flow, $f_{\mathrm{u}}$ is the unbound fraction of metoprolol in the blood, and $C L_{\text {int }}$ is the intrinsic hepatic clearance of the drug. In addition, assuming that there is no extrahepatic metabolism (excretion), $C L / F$ can be described by the following equation ${ }^{24)}$ :

$$
C L / F=f_{\mathrm{u}} \cdot C L_{\text {int }}
$$

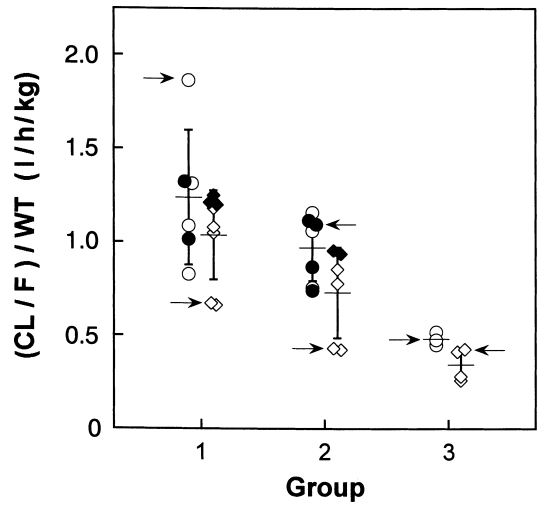

Fig. 5. Effects of CYP2D6*2 and the CYP2C19 Genotypes on the Oral Clearance of Metoprolol

Circles indicate the younger ( $56-70$ years old) patients, and diamonds indicate the older ( $71-83$ years old) patients in each Group. Open symbols: CYP2D $6 * 1 / * 1$ (Group 1a), $C Y P 2 D 6^{*} 1 / * 10$ (Group 2a), or $C Y P 2 D 6^{*} 10 / * 10$ (Group 3); solid symbols: $C Y P 2 D 6^{*} 1 / * 2$ (Group 1b) or CYP2D6*2/*10 (Group 2b). The arrows indicate poor metabolizers of CYP2C19. Bars indicate the mean \pm S.D. for each group.

Since the bound fraction of metoprolol in human plasma is only $12 \%,{ }^{13}$ ) the alteration of plasma protein binding of the drug would have little influence on the $C L / F$ value. In contrast, a reduced $C L_{\text {int }}$ value caused by $C Y P 2 D 6^{*} 10$ and aging can lead to a decrease in the $C L / F$ value. Fukuda et al. suggested that decreased drug clearance due to CYP2D6*10 could be caused by the low expression and affinity of CYP2D6. ${ }^{25)}$ In addition, Castleden et al. suggested that hepatic metabolism and extraction during the first pass of the CYP2D6 substrate, propranolol, is decreased by aging. ${ }^{26,27)}$

Ward et al. reported that 4-hydroxylation of propranolol, structurally similar to metoprolol, is catalyzed by CYP2D6, but side-chain oxidation of the drug is catalyzed in part by CYP2C19. ${ }^{28)}$ Consequently, the metabolic clearance of sidechain oxidation of propranolol was 55\% less in the poor metabolizers of CYP2C19 than in the extensive metabolizers of CYP2C19. ${ }^{28)}$ On the other hand, metoprolol is mainly metabolized by the three routes of $O$-demethylation, $\alpha$-hydroxylation, and $N$-dealkylation, and these metabolites are excreted in the urine ${ }^{29)} \mathrm{N}$-Dealkylation of metoprolol is mediated by CYP2D6 and also CYP2C19. ${ }^{17)}$ However, Regårdh and Johnsson reported that $O$-demethylation and $\alpha$-hydroxylation are mediated by CYP2D6, and that the metabolites formed by these mechanisms account for $70 \%$ of the urinary recovery of metoprolol doses. ${ }^{13)}$ These reports suggest that metoprolol is mainly metabolized by CYP2D6, which is consistent with the present finding that CYP2C19 genotype showed no significant effect on the $C L / F$ values of metoprolol (Table 1, Fig. 4).

Table 3 summarizes the $C L / F$ and $V / F$ values in a typical patient for Groups 1, 2, and 3, where the pharmacokinetic parameters in the younger ( $\leq 70$ years old) and also older ( $>70$ years old) patients were obtained from population estimates for Model 9 (Table 2). The $C L / F$ and $V / F$ values listed in Table 3 were almost identical to the mean $C L / F$ and $V / F$ values shown in Figs. 3 and 4. In the present study, the hepatic clearance of metoprolol could be interpreted physiologically, because the blood metoprolol concentrations were used for the pharmacokinetic analysis. ${ }^{14,24)}$ Then, the $F$ values were estimated using Eqs. 5 and 6, assuming that the $Q_{\mathrm{h}}$ value in a typical younger ( $\leq 70$ years old) and older $(>70$ 
Table 3. Physiological Pharmacokinetic Parameters of Metoprolol

\begin{tabular}{|c|c|c|c|c|c|c|c|}
\hline \multirow{2}{*}{\multicolumn{2}{|c|}{ Parameters }} & \multicolumn{2}{|c|}{ Group 1} & \multicolumn{2}{|c|}{ Group 2} & \multicolumn{2}{|c|}{ Group 3} \\
\hline & & $56 \leqq A G E \leqq 70$ & $70<A G E \leqq 83$ & $56 \leqq A G E \leqq 70$ & $70<A G E \leqq 83$ & $56 \leqq A G E \leqq 70$ & $70<A G E \leqq 83$ \\
\hline$C L / F$ & $(1 / \mathrm{h} / \mathrm{kg})$ & 1.38 & 1.02 & 0.938 & 0.693 & 0.499 & 0.369 \\
\hline$V / F$ & $(1 / \mathrm{kg})$ & 5.16 & 5.16 & 4.52 & 4.52 & 3.88 & 3.88 \\
\hline$Q_{\mathrm{h}}$ & $(1 / \mathrm{h} / \mathrm{kg})$ & 1.29 & 1.02 & 1.29 & 1.02 & 1.29 & 1.02 \\
\hline$F$ & & 0.484 & 0.500 & 0.579 & 0.595 & 0.721 & 0.734 \\
\hline$C L$ & $(1 / \mathrm{h} / \mathrm{kg})$ & 0.666 & 0.509 & 0.543 & 0.413 & 0.360 & 0.271 \\
\hline V & $(1 / \mathrm{kg})$ & 2.49 & 2.58 & 2.62 & 2.69 & 2.80 & 2.85 \\
\hline
\end{tabular}

years old) patient is $1.29 \mathrm{l} / \mathrm{h} / \mathrm{kg}$ and $1.02 \mathrm{l} / \mathrm{h} / \mathrm{kg}$, respectively. ${ }^{30)}$ In addition, the systemic clearance $(C L)$ and volume of distribution $(V)$ were calculated as follows:

$$
\begin{aligned}
& C L=F \cdot C L / F \\
& V=F \cdot V / F
\end{aligned}
$$

Table 3 also lists the $Q_{\mathrm{h}}, F, C L$, and $V$ values for Groups 1, 2, and 3 . The calculated $F$ values for Group 1 were significantly lower than those for Group 2, and the calculated $F$ values for Group 3 were significantly higher than those for Group 2. Interestingly, no significant difference in the $F$ values was observed between the younger ( $\leq 70$ years old) and older $(>70$ years old) patients. In contrast, the calculated $C L$ values for Group 1 were higher than those for Group 2, and the calculated $C L$ values for Group 3 were lower than those for Group 2 . The calculated $C L$ values in the younger ( $\leq 70$ years old) patients were higher than those in older $(>70$ years old) patients (Table 3 ). Accordingly, we thought that the significant effect of the $C Y P 2 D 6^{*} 10$ genotype on the $C L / F$ value was probably due not only to the decrease in $C L$ but also to the increase in $F$. On the other hand, the significant effect of aging on $C L / F$ was thought to be mainly due to the decrease in $C L$. In addition, we thought that the increase in $F$ was mainly responsible for the significant effect of the $C Y P 2 D 6^{*} 10$ genotype on the $V / F$ value, because it was unlikely that a genetic mutation in CYP2D6 would affect $V$ of the drug. ${ }^{11,31)}$ However, the calculated $V$ slightly fluctuated by the $C Y P 2 D 6^{*} 10$ genotype, which might be attributed to estimation errors in the $C L / F$ and/or $V / F$ values (Table 3 ). That is, approximation errors could lie in the assumptions that the disposition of orally administered metoprolol is described by the one-compartment model with bolus input, that the gastrointestinal absorption of the drug is complete, that nonhepatic elimination of the drug is negligible, or that the hepatic extraction process is described by the well-stirred model. ${ }^{12,14,19)}$

Metoprolol has been administered to Caucasian patients with heart failure at the dose range of $12.5-200 \mathrm{mg} / \mathrm{d},{ }^{32,33}$ ) and with hypertension at the dose range of 75 $450 \mathrm{mg} / \mathrm{d} .{ }^{34,35)}$ In the present study, middle-aged and elderly Japanese patients were routinely treated at a lower dose range of $40-120 \mathrm{mg} / \mathrm{d}$, and no adverse effect of metoprolol was observed in Groups 1, 2, and 3. However, careful dose titration is necessary to treat Japanese patients at the relatively higher doses of metoprolol, because the gene frequency of $C Y P 2 D 6^{*} 10$ in Japanese is higher than that in Caucasians. ${ }^{1,8-10)}$ In addition, the genotyping of CYP2D6 may be useful in designing the dosage of metoprolol for Japanese patients and in determining which patients are at risk for ad- verse effects.

In conclusion, we systematically estimated the variability of the pharmacokinetics of metoprolol in routinely treated middle-aged and elderly Japanese patients using the NONMEM approach. Our findings indicate that the CYP2D $6 * 10$ allele and aging are the major factors that affects the pharmacokinetic variability of metoprolol. The results also suggest that the pharmacokinetics of metoprolol in Japanese extensive metabolizers of CYP2D6 is different from that in Caucasian extensive metabolizers because of the large interethnic difference in the gene frequency of $C Y P 2 D 6 * 10$.

Acknowledgements This work was supported in part by a Grant-in-Aid for Scientific Research from Japan Society for the Promotion of Science (JSPS).

\section{REFERENCES}

1) Bradford L. D., Pharmacogenomics, 3, 229-243 (2002).

2) Bertilsson L., Lou Y. Q., Du Y. L., Liu Y., Kuang T. Y., Liao X. M., Wang K. Y., Reviriego J., Iselius L., Sjöqvist F., Clin. Pharmacol. Ther, 51, 388-397 (1992).

3) Nakamura K., Goto F., Ray W. A., McAllister C. B., Jacqz E., Wilkinson G. R., Branch R. A., Clin. Pharmacol. Ther, 38, 402-408 (1985).

4) Huang J. D., Chuang S. K., Cheng C. L., Lai M. L., Clin. Pharmacol. Ther., 65, 402-407 (1999).

5) Johansson I., Lundqvist E., Bertilsson L., Dahl M. L., Sjöqvist F., Ingerman S. M., Proc. Natl. Acad. Sci. U.S.A., 90, 11825-11829 (1993).

6) Yokota H., Tamura S., Furuya H., Kimura S., Watanabe M., Kanazawa I., Kondo I., Gonzalez F. J., Pharmacogenetics, 3, 256-263 (1993).

7) Johansson I., Oscarson M., Yue Q. Y., Bertilsson L., Sjöqvist F., Ingerman S. M., Mol. Pharmacol., 46, 452-459 (1994).

8) Tateishi T., Chida M., Ariyoshi N., Mizorogi Y., Kamataki T., Kobayashi S., Clin. Pharmacol. Ther, 65, 570-575 (1999).

9) Nishida Y., Fukuda T., Yamamoto I., Azuma J., Pharmacogenetics, 10, $567-570$ (2000).

10) Roh H. K., Chung J. Y., Oh D. Y., Park C. S., Svensson J. O., Dahl M. L., Bertilsson L., Br. J. Clin. Pharmacol., 52, 265-271 (2001).

11) Taguchi M., Nozawa T., Kameyama T., Inoue H., Takesono C., Mizukami A., Hashimoto Y., Eur. J. Clin. Pharmacol., 59, 385-388 (2003).

12) Regårdh C. G., Borg K. O., Johansson R., Johansson G., Palmer L., J. Pharmacokinet. Biopharm., 2, 347-364 (1974).

13) Regårdh C. G., Johnsson G., Clin. Pharmacokinet., 5, 557-569 (1980).

14) Wilkinson G. R., Shand D. G., Clin. Pharmacol. Ther., 18, 377-390 (1975).

15) Regårdh C. G., Landahl S., Larsson M., Lundborg P., Steen B., Hoffmann K. J., Lagerström P. O., Eur. J. Clin. Pharmacol., 24, 221-226 (1983).

16) Kendall M. J., Brown D., Yates R. A., Br. J. Clin. Pharmacol., 4, 497499 (1977).

17) Rendic S., Drug. Metab. Rev., 34, $83-448$ (2002). 
18) Luzier A. B., Killian A., Wilton J. H., Wilson M. F., Forrest A., Kazierad D. J., Clin. Pharmacol. Ther, 66, 594 601 (1999).

19) Johnsson G., Regårdh C. G., Sölvell L., Acta Pharmacol. Toxicol., 36 (Suppl. V), 31-44 (1975).

20) Lamba J. K., Dhiman R. K., Kohli K. K., Clin. Pharmacol. Ther, 68 , $328-335(2000)$

21) Hamelin B. A., Bouayad A., Méthot J., Jobin J., Desgagnés P., Poirier P., Allaire J., Dumesnil J., Turgeon J., Clin. Pharmacol. Ther, 67, 466-477 (2000)

22) Sheiner L. B., Beal S. L., J. Pharmacokin. Biopharm., 11, 303-319 (1983).

23) Beal S. L., Boeckmann A. J., Sheiner L. B., "NONMEM Users Guides: NONMEM Project Group," University of California, San Francisco, 1992.

24) Wilkinson G. R., Pharmacol. Rev., 39, $1-47$ (1987).

25) Fukuda T., Nishida Y., Imaoka S., Hiroi T., Naohara M., Funae Y., Azuma J., Arch. Biochem. Biophys., 380, 303-308 (2000).

26) Castleden C. M., Kaye C. M., Parsons R. L., Br. J. Clin. Pharmacol., 2, 303-306 (1975).
27) Castleden C. M., George C. F., Br. J. Clin. Pharmacol., 7, 49-54 (1979).

28) Ward S. A., Walle T., Walle U. K., Wilkinson G. R., Branch R. A., Clin. Pharmacol. Ther, 45, 72-79 (1989).

29) Borg K. O., Carlsson E., Hoffmann K. J., Jönsson T. E., Thorin H., Wallin B., Acta Pharmacol. Toxicol., 36, 125-135 (1975).

30) Zoli M., Magalotti D., Bianchi G., Gueli C., Orlandini C., Grimaldi M., Marchesini G., Age and Ageing, 28, 29-33 (1999).

31) Kirchheiner J., Müller G., Meineke I., Wernecke K. D., Roots I., Brockmöller J., J. Clin. Psychopharmacol., 23, 459-466 (2003).

32) MERIT-HF study group, Lancet, 353, 2001-2007 (1999).

33) Poole-Wilson P. A., Swedberg K., Cleland J. G., Di Lenarda A., Hanrath P., Komajda M., Lubsen J., Lutiger B., Metra M., Remme W. J., Torp-Pedersen C., Scherhag A., Skene A., Carvedilol Or Metoprolol European Trial Investigators, Lancet, 362, 7-13 (2003).

34) Bergstrand R. H., Vedin J. A., Wilhelmsson C. E., Berglung G., Eur. J. Clin. Pharmacol., 10, 375-379 (1976).

35) Tuomilehto J., Pohjola M., Ann. Clin. Res., 10, 24-29 (1978). 